\title{
МЕДИАПСИХОЛОГИЯ 2020: НОВЫЙ КОНТЕКСТ ЗАДАЧ И НАПРАВЛЕНИЙ ИССЛЕДОВАНИЙ
}

\section{MEDIA PSYCHOLOGY IN 2020: NEW CONTEXT OF PROBLEMS AND AREAS OF RESEARCH}

\section{Zhizhina}

Summary: The article outlines the current tasks and research directions of media psychology, analyzes the negative and positive effects of mass media in the context of the crisis situation in 2020 related to the pandemic. In connection with the spread of infodemia and the complexity of the media space, the practical significance of media education is emphasized, the main strategic goal of which is to form the media competence of the individual responsible for the psychological security of a person in the media world. In the current environment, the contradictory role of mass media is more evident than ever before. the data available in scientific research indicate a complex relationship between the risks, negative effects and benefits, and positive effects of human use of mass media. The author has identified psychological patterns that cause greater vulnerability to risks and negative consequences of some users, and greater susceptibility of other users to get a positive effect from the use of media, which remains the most important task of media psychology.

Keywords: media psychology, media psychotherapy, personality, mass media effects, psychological education, psychological assistance.

\author{
Жижина Мария Викторовна \\ К.п.н., дочент, Саратовский национальный \\ исследовательский государственный \\ университет им Н.Г. Чернышевского \\ Zhizhina5@mail.ru
}

Аннотация: В статье обозначены актуальные задачи, направления исследований медиапсихологии, анализируются негативные и позитивные эффекты массмедиа, в контексте кризисной ситуации 2020 года, связанной с пандемией. В связи с распространением инфодемии и усложнением медиапространства подчеркивается практическая значимость медиаобразования, основной стратегической целью которого является формирование медиакомпетентности личности, отвечающей за психологическую безопасность человека в мире медиа. В текущих условиях как никогда ранее проявляется противоречивая роль массмедиа, имеющиеся в научных исследованиях данные свидетельствуют о сложной взаимосвязи между рисками, негативными эффектами и выгодами, позитивными эффектами от использования массмедиа человеком. Автором выявлены психологические закономерности, обуславливающие большую уязвимость к рискам и негативным последствиям одних, и большую восприимчивость других пользователей к получению позитивного эффекта от использования медиа, остается важнейшей задачей медиапсихологии.

Ключевые слова: медиапсихология, медиапсихотерапия, личность, эффекты массмедиа, психологическое просвещение, психологическая помощь.
$\mathrm{B}$ настоящее время в отечественной медиапсихологии, как науке о личности, включенной в контекст современной медиакультуры выделены три основных направления исследований: медиааналитика (анализ контекста массовой коммуникации с точки зрения соблюдения принципов информационно-психологической безопасности, интересов и прав аудитории); медиаобразование (формирование навыков использования СМИ в интересах потребителей, овладение антиманипулятивными стратегиями); медиатерапия (обеспечение коллективного восстановления и реабилитации посредством массмедиа) [4]. В предметное поле медиапсихологии входит анализ психологических закономерностей отношений, поведения, самочувствия человека в усложняющемся медиапространстве, и конкретно - в системах медиавосприятия, медиапотребления, медиапроизводства и медиаобразования.

Медиа и ранее определяли доминирующие тенденции в общественном восприятии социально значимых проблем и служили фактором конструирования реальности, формирования установок в отношении тех или иных проблем, но сегодня можно с уверенностью гово- рить о значительном возрастании роли медиа (ценности медиа как средства коммуникации и достижения конкретных целей и результатов) как в жизни отдельного человека, так и в жизнедеятельности организаций, перешедших на дистанционную форму работы.

Пандемия Covid-19 сопровождается «инфодемией» данный термин был введен Всемирной Организацией Здравоохранения, для обозначения текущей ситуации, характеризующейся переизбытком как онлайновой, так и офлайновой информации, которая может быть не только достоверной. Более того, Всемирная Организация Здравоохранения официально признала инфодемию, проявляющуюся в страхах, нагнетании обстановки, искажении информации серьезной угрозой человечеству. В психологической науке хорошо известен феномен под названием - «смерть от ожидания смерти». Эффект инфодемии как действие информационного вируса может нанести массово огромный вред людям, не меньше реального вируса, провоцируя возникновение тревоги, панических атак, стресса и других психологических феноменов, ведущих как минимум к снижению иммунитета. 
Другими словами, в сегодняшних условиях как никогда ранее проявляется противоречивая роль массмедиа: с одной стороны, медиа выполняя информационную, развлекательную, коммуникативную, мобилизационную, поддерживающую функции, играют важную позитивную роль в жизни человека, а с другой стороны, проявляя себя в качестве фактора дезинформации, усугубления негативных эмоциональных состояний, возникновения панических настроений в обществе, выполняют негативную роль.

На наш взгляд, особую значимость сегодня приобретает анализ тех вопросов, которые связаны с изучением влияния медиа на психологическое самочувствие и благополучие человека. Имеющиеся в научных исследованиях данные свидетельствуют о сложной взаимосвязи между рисками, негативными эффектами и выгодами, позитивными эффектами от использования массмедиа человеком. Следовательно, одной из важнейших задач медиапсихологии является большее понимание процессов, обуславливающих позитивный и негативный эффекты, а также анализ индивидуальных различий, детерминирующих риски и восприимчивость пользователей.

Современный человек проводит много времени в медиа пространстве, находясь под влиянием нескончаемого информационного потока, что, в свою очередь, порождает искажения в восприятии жизненной среды, влияя на когнитивные компетенции. Установлено также, что манипулятивный эффект медиа возрастает в условиях информационной перегрузки преимущественно негативного содержания. Учитывая проблему манипуляции общественным сознанием, которая при современных технических возможностях новых медиа становится более эффективной и масштабной, и значительное распространение инфодемии, можно говорить об актуализации практической значимости такого направления медиапсихологии как медиаобразование населения. Основной стратегической целью медиаобразования является формирование медиакомпетентности личности, отвечающей за психологическую безопасность человека в медиа среде.

Сегодня проблемы медиапсихологической безопасности личности приобретают новое и еще более актуальное звучание, чем когда бы то ни было, что обусловлено стремительным развитием информационных технологий. Особенно ярко такие технологии применяются в новых социальных медиа, которые в силу своей специфики (интерактивности, мультимедийности и др.) становятся сложным современным социальным инструментом, позволяющим воздействовать на настроения в обществе, формировать мнение масс, актуализировать те или иные события. Подобные тенденции привели к возникновению глобального информационного пространства, в котором используются различные средства и технологии манипуляций сознанием человека. Интенсификации данных явлений и процессов остро ставит вопрос о необходимости защитить человека от негативного воздействия массмедиа.

Новое звучание проблемы медиабезопасности личности, а точнее ее практическая значимость в реалиях сегодняшнего дня, обусловлено многими факторами:

- многократное увеличение информационных потоков - поступающий информационный массив в многократно превосходит возможности психики к ее осмысленной переработке;

- постоянно появляющиеся новые технические возможности медиа, которые обеспечивают интерактивность и при этом создают порой иллюзию сопричастности человека к происходящим событиям, с ощущением включенности;

- скорость распространения информации или эффект «снежного кома» (преувеличение значимости новости, ее драматизация и молниеносное распространение) - создает ложное представление о том, что новость является не только реальной, но и значимой для большинства;

- возрастающая медиавовлеченность человека в медиасреду провоцирует усиление информационно-психологической усталости, на фоне которой резко возрастают манипулятивные возможности массмедиа;

- расширение социального пространства личности, и как следствие увеличение числа агентов влияния, которое произошло из-за взрыва авторства в медиасреде;

- минимизация личного пространства в контексте медиасреды, за счет чего возрастает уровень доверия к создателю медиаконтента (например, блогеру рекламирующему тот или иной товар или услугу), а также размывание психологических границ и минимизация личного пространства, в следствии чего, изменяется отношения к приватности;

- представления человека о своей медиакомпетентности и умении самостоятельно дифференцировать фейковые новости от реальных, а также способности противостоять различным манипулятивным стратегиям.

Субъективные самооценки человека уровня своей медиакомпетентности не всегда отражают реальный уровень его медиазащищенности, более того, ошибочные представления могут вводить человека не только в иллюзии, повышать уровень доверия к медиакоммуникантам, медиатекстам, но и ставить под угрозу его личную медиабезопасность [1].

Учитывая сегодняшние кризисные условия, также с уверенностью можно говорить о медиапсихотерапии как об актуальном и значимом направлении современ- 
ной психологии в целом. Известно, что в условиях экстремальных и чрезвычайных ситуаций психологическая помощь становится особенно важной. Стремительно возросшая в текущем году потребность населения в психологической помощи является ярким тому подтверждением. Не случайно вопросы психического здоровья и психосоциальной поддержки относятся к ключевым моментам всех мер, принимаемых в мире для борьбы с пандемией. [6].

Сложившаяся в мире ситуация с пандемией короновируса активизировала всевозможные стрессовые факторы и показала наличие глобальной потребности в развитии психологической грамотности и повышения психологической культуры населения. Массированный поток негативной, пугающей, противоречивой и порой недостоверной информации, провоцирующий распространение тревожных, а порой панических состояний, новизна и непредсказуемость ситуации, изменения в жизненном укладе (социальная дистанцированность, изоляция, ограничения, работа в дистанционном режиме и в условиях самоизоляции, изменения в уровне дохода, отсутствие полноценного привычного отдыха и др.), - все эти социальные, экономические и психологические факторы способствуют усугублению негативных психических состояний, повышению уровня тревожности личности, а иногда и возникновению депрессивных состояний.

Сегодняшние кризисные явления подтвердили необходимость усиления активной работы в направлении применения техник терапии и психологического просвещения населения, следствием которых может стать повышение стрессоустойчивости за счет обучения навыкам совладающего поведения и методам саморегуляции. Это, в частности, становится возможным за счет развития техники и технологий цифровизации психологической помощи, в том числе, за счет расширения форматов деятельности и использования психологами различных медиатехнологий. Учитывая особенности и чрезвычайный характер современной ситуации, все большую медиавовлеченность человека в виртуальный мир и глобальный характер пандемии, использование различных медиаплощадок и медиапрограмм будет способствовать повышению эффективности просветительской деятельности психолога и популяризации психологической помощи.

В условиях экстремальных и чрезвычайных ситуаций развитие медиапсихотерапии, купирование негативных эффектов становится принципиально важным с практической точки зрения, как минимум, в плане:

- использования психотерапевтического потенциала медиа с целью снижения и минимизации негативных эффектов не только самих массмедиа, но и последствий кризисных ситуаций;
- рассмотрения массмедиа как инструмента (средства) решения задач, связанных с психологическим просвещением населения.

- использования массмедиа как площадки оказания профессиональной психологической помощи и поддержки.

В отечественных психологических исследованиях практически не представлен психотерапевтический потенциал медиа в условиях повышенной стрессогенности. Безусловно развитие данного направления невозможно без психологического просвещения и реализации двух других основных направлений медиапсихологии, таких как медианалитика и медиаобразование. В то же время, в единичных российских научных публикациях (Ю.А. Вербицкая, В.Г. Иванов, В.Ю. Меновщиков, Е.И. Пронин, Е.Е. Пронина) активно поднимается проблема медиапсихотерапии, в задачи которой входит профилактика, реабилитация медиатравм и психологическое восстановление посредством медиакоммуникаций. Так, Е.Е. Пронина говорит о том, что в период самоизоляции именно социальные сети явились примером реальной медиатерапии, так как для них приоритетом выступают интересы самой аудитории, в отличие от СМИ, которые не используют имеющиеся наработки психотерапии. «Именно в социальных сетях можно увидеть сегодня все копингстратегии, которые известны психологии и убедительно демонстрируют самоорганизацию и дееспособность социума в борьбе с экстремальными обстоятельствами» $[5]$.

В работах отечественных авторов (В.Г. Иванов, Е.Ю. Лазарева, Е.Л. Николаев) анализируются вопросы, связанные с применением медиатехнологий в психотерапевтической и психологической практике [2]. В частности, В.Ю. Меновщиков [3] подробно рассматривает возможности и ограничения помощи посредством интернет-технологий, включающих как средства дистанционной коммуникации, так и программы самопомощи и самодиагностики.

На наш взгляд, особую значимость сегодня приобретает анализ тех, вопросов, которые связаны с изучением влияния медиа на психологическое самочувствие и благополучие человека. Имеющиеся в научных исследованиях данные свидетельствуют о сложной взаимосвязи между рисками, негативными эффектами и выгодами, позитивными эффектами от использования массмедиа человеком. Следовательно, для лучшего понимания основных процессов, которые управляют этими эффектами, а также с целью понимания индивидуальных различий, которые обуславливают большую уязвимость к рискам одних пользователей и большую восприимчивость других - к выгодам, получению позитивных эффектов от использования медиа, остается важнейшей задачей медиапсихологии. 
Учитывая дистанционный формат обучения, на который вынуждено перешли многие вузы, перед медиапсихологией встает практическая задача, связанная с разработкой эффективных шагов по созданию медиасообществ, которые будут ориентированы на интеграцию и психологическую поддержку студентов в условиях дистанционного обучения. Таким образом, сегодняшняя кризисная ситуация с пандемией поставила перед медиапсихологией много новых задач с неизвестными слагаемыми, и в целом вопросов оказалось больше, чем ответов.

Тем не менее, уже сейчас со всей очевидностью можно говорить об актуализации массмедиа как неотъемлемой части социального института оказания психологической помощи и поддержки так же, как эффективным инструментом решения новых задач, связанных с психологическим просвещением.

Наряду с этим сегодняшняя ситуация переопределила ряд значимых с прикладной точки зрения проблем, которые и до этого были на авансцене медиапсихологии, но теперь для эффективной помощи человеку особую значимость приобретает направление медиапсихологии, связанное с медиатерапией и формированием новых образцов совладающего поведения.

В заключение отметим, что реализация медиапсихотерапии как направления медиапсихологии может быть осуществлена в проектной форме в виде разработок системы мер и специальных, в том числе, компьютерных медийных программ по реабилитации и профилактике возможных рисков и медиатравм, то есть, с помощью организации в медиапространстве масштабной инфор- мационной, методической работы, в том числе, направленной на психологическую профилактику вероятных негативных последствий кризисных ситуаций и просвещение населения в новых формах адаптивного поведения.

Таким образом, перед медиапсихологией встает реальная необходимость анализа ряда психологических задач, среди них:

- анализ медиа как психотерапевтического фактора, раскрытие потенциальных возможностей медиа в просветительской деятельности, в оказании психологической помощи и поддержки;

- формирование и понимание новых форм (защитного и совладающего, адаптивного) поведения в медиасреде;

- разработка программ по формированию медиакомпетентности как фактора обеспечивающего медиаиммунитет личности;

- процессы формирования социальных представлений личности о массмедиа;

- анализ массмедийного воздействия на психологическое самочувствие, благополучие и социальное поведение человека, и конкретно, изучение сложного и неоднозначного влияния медиа на современного человека - с учётом как негативных, так и позитивных эффектов, возникающих в процессе взаимодействия с медиа;

- вскрытие психологических механизмов, определяющих большую уязвимость одного человека к рискам и негативным эффектам медиа, и наоборот - на большую восприимчивость другого человека к позитивным эффектам медиа.

\section{ЛИТЕРАТУРА}

1. Жижина М.В. Коммуникационная парадигма «многие-многим» или новое звучание проблемы медиабезопасности личности // Медиа в современном мире. 58-е Петербургские чтения Сборник материалов Международного научного форума. В 2-х томах. Ответственный редактор В.В. Васильева. СПб., 2020. C. 191-192.

2. Иванов В.Г., Лазарева Е.Ю., Николаев Е.Л. Применение современных информационно-коммуникационных технологий в психотерапевтической и психологической практике (обзор зарубежных исследований) // Проблемы современного педагогического образования. 2017. Т. 57. № 6. С. 321 -329.

3. Меновщиков В.Ю. Психологическая помощь в сети Интернет. [Электронный ресурс]. М., 2007. 178 c. URL: http://flogiston.ru/articles/netpsy/psyhelp_in_ internet (дата обращения: 31.10.2019).

4. Пронин Е.И., Пронина Е.Е. Медиапсихология: новейшие информационные технологии и феномен человека // Общественные науки и современность. 2013. — № 2. - С. 151-162.

5. Пронина Е.Е. Новые и старые медиа в условиях кризиса: игра на выбывание //Организационная психология: люди и риски: сб. материалов XI Международной научно-практической конференции (24 апреля - 1 мая 2020 г.)/ под ред. проф. Л.Н. Аксеновской. - Саратов: ИЦ «Наука», 2020. С. 170-176.

6. Эксперт В03: Covid-19 разрушает не только организм, но и психику // [электронный ресурс] https://news.un.org/ru/interview/2020/05/1378122 